\title{
Investigation of Magnetite Oxidation Kinetics at the Particle Scale
}

\author{
T.K. SANDEEP KUMAR, N.N. VISWANATHAN, H. AHMED, A. DAHLIN, \\ C. ANDERSSON, and B. BJORKMAN
}

The induration of magnetite pellets is a complex physico-chemical process that involves oxidation, sintering, and heat transfer. The thermal- and gas-composition profile that is experienced by the pellet in an induration reactor could result in the formation of a homogenous or heterogeneous pellet structure, which could affect the pellet quality. The oxidation kinetics of magnetite pellets from sintering studies have been studied at two levels, namely, the pellet scale and at the particle scale, and the findings of the latter are presented here. The rate of oxidation of the magnetite concentrate depends primarily on temperature, oxygen content in the oxidizing gas, and particle size. These factors are investigated in this study. It was found that the oxidation of the magnetite concentrate is comprised of two distinct stages, a primary stage with high rates followed by a secondary stage where rates decrease significantly. The isothermal oxidation behavior as analyzed by the Avrami kinetic model was found to fit better than the shrinking-core model. The partially oxidized particles were examined microstructurally to supplement the experimental and model results. The Avrami kinetic model for isothermal oxidation was extended to non-isothermal profiles using the superposition principle, and the model was validated experimentally.

https://doi.org/10.1007/s11663-018-1459-5

(C) The Author(s) 2018

\section{INTRODUCTION}

THE pelletization of iron-ore fines is one of the widely practiced agglomeration techniques in iron and steel making because it enables the use of a very fine concentrate. Iron-ore pellets offer several advantages over other ferrous burdens in terms of strength, reducibility and uniformity of shape (spherical), chemistry, and porosity. Magnetite pelletization provides an added benefit in terms of energy, owing to the exothermic nature of its oxidation to hematite. ${ }^{[1]}$ Magnetite ore that is excavated from mines is crushed, beneficiated, and ground into fines concentrate. The concentrate is balled into green pellets with the addition of moisture and additives, such as flux and binder. Thereafter, green pellets are fired in an induration furnace to impart

T.K. SANDEEP KUMAR, C. ANDERSSON, and B. BJORKMAN are with the Lulea University of Technology (LTU), 97187 Lulea, Sweden. Contact e-mail: kamesh.sandeep@ltu.se N.N. VISWANATHAN is with the Indian Institute of Technology Bombay (IITB), Mumbai 400076, India. H. AHMED is with the Lulea University of Technology (LTU) and also with the Center of Metallurgical Research and Development Institute, Cairo 11421, Egypt. A. DAHLIN is with the Luossavaara-Kiirunavara Aktiebolag (LKAB), 98381 Malmberget, Sweden.

Manuscript submitted February 24, 2018.

Article published online November 27, 2018. sufficient strength and to attain the desired properties. During induration, green pellets that are laid as a packed bed undergo updraft and downdraft drying [room temperature to $523 \mathrm{~K}\left(250^{\circ} \mathrm{C}\right)$ ] followed by oxidation $\left[573 \mathrm{~K}\right.$ to $1023 \mathrm{~K}\left(300{ }^{\circ} \mathrm{C}\right.$ to $\left.\left.750{ }^{\circ} \mathrm{C}\right)\right]$ and finally sintering $\left[>1273 \mathrm{~K}\left(1000^{\circ} \mathrm{C}\right)\right] . .^{[2]}$ The hot gases are allowed to flow in the counter-current direction across the furnace for efficient heat transfer.

To achieve and enhance stability in the production of homogeneous and good-quality pellets, a model is required to predict the optimum thermal and gaseous profile for pellets during induration. Therefore, it is necessary to understand and estimate the kinetics of the phenomena involved in magnetite pellet induration. The methodology used was to investigate each of the phenomena (oxidation, sintering, and heat transfer) on a single pellet in isolation, and subsequently integrate these to develop the overall induration model. Sintering models at the single-pellet scale have already been developed on the basis of their kinetics, and have been demonstrated in previous studies. ${ }^{[3,4]}$ The oxidation kinetic model for magnetite pellets has been developed in two parts. We investigated the oxidation phenomenon of magnetite concentrate from the Luossavaara-Kiirunavara Aktiebolag (LKAB) mine in Malmberget, Sweden at the particle scale; estimated the oxidation kinetics; and determined the responsible mechanisms. 
The kinetics that were estimated in this study will help to establish the oxidation behavior of magnetite at the pellet scale, which will be communicated in future.

From the early 1950s, several researchers have studied the oxidation of magnetite pellets and investigated the effect of different sources of concentrate, pellet, and particle-size distribution with respect to various thermal atmospheres. ${ }^{[2,5-12]}$ Many experimental studies have captured the oxidation behavior of magnetite at the pellet scale, although limited studies have been conducted at the particle scale to understand their behavior and estimate their kinetics to develop and validate the model. ${ }^{[2,5-7,9,13-15]}$ Magnetite oxidation proceeds with high initial rates and plateaus at the later stages of oxidation at a significantly slower rate. Magnetite-concentrate oxidation can be simulated for non-catalytic heterogeneous gas-solid reactions. Several models have been proposed to follow the gas-solid reaction sequence, which provides insight into the dominant mechanism in the range of variables studied. ${ }^{[12,13,16-20]}$

One of the gas-solid reaction models, the shrinking-core model (SCM), postulates that the oxidation of magnetite concentrate proceeds topo-chemically from the surface towards the center of the particle in an isothermal atmosphere, as described in Eq. [1]. ${ }^{[21]} \mathrm{It}$ postulates that the mass transfer of the oxidizing gas from the bulk to the particle surface is rate determining initially. When oxygen gas reaches the particle surface, the interfacial chemical oxidation reaction of magnetite to hematite becomes dominant with a release of exothermic energy. Thereafter, oxygen diffuses into the particle through the grain boundaries or via microcracks in the hematite product layer because of the concentration gradient, and proceeds concentrically towards the center of the particle. This results in a higher degree or rate of oxidation at the beginning, and a plateau at the later stage.

$$
\begin{aligned}
& \frac{r}{3 k_{\mathrm{m}}} f+\frac{r}{k_{\mathrm{R}}}\left[1-(1-f)^{\left(\frac{1}{3}\right)}\right]+\frac{r^{2}}{6 k_{\mathrm{S}}}\left[3-2 f-3(1-f)^{\left(\frac{2}{3}\right)}\right] \\
& \quad=\frac{C M}{\rho_{\mathrm{B}}} t,
\end{aligned}
$$

where $f$ is the fraction of conversion for a concentrate that comprises particles with an average radius $r$ for an isothermal time $t$ and $k_{\mathrm{M}}, k_{\mathrm{R}}$, and $k_{\mathrm{S}}$ are the rate constants for the mass transfer of oxidizing gas to the particle surface, chemical reaction at the interface, and diffusivity, respectively. $M$ and $\rho_{\mathrm{B}}$ are the molar mass and density of the reactant concentrate, respectively, and $C$ is the oxygen concentration in the reacting gas.

Forsmo $^{[1]}$ studied the oxidation and sintering phenomena for magnetite pellets prepared from magnetite concentrates of varying fineness to understand the mechanisms and to optimize the particle-size distribution or fineness desired to achieve good-quality product pellets. Thereafter, Cho investigated the isothermal oxidation kinetics of magnetite and developed the pellet-particle model. ${ }^{[22]}$ Monsen et al. ${ }^{[15]}$ investigated the kinetics of magnetite oxidation at the particle scale for a narrow-size-fraction concentrate from different mines. They hypothesized that magnetite-particle oxidation proceeds in a topo-chemical manner with growth of the hematite product layer. They found that the magnetite oxidizes at a rapid rate initially, probably because of the fine particles in the concentrate, and a plateau is reached during the later stages owing to solid-state diffusion in larger particles, according to the SCM. It was inferred that the plateau behavior can be controlled by the concentrate particle-size distribution and, thus, the fraction of particles oxidized. However, it was observed that the needle-like structure of the hematite grew ahead of the reaction front, which indicates that the reaction may proceed by another mechanism. Monazam et al. ${ }^{[23]}$ examined the oxidation of secondary magnetite (i.e., reduced-hematite) particles during chemical-looping combustion to understand the reaction mechanisms by applying several gas-solid reaction-kinetic models. They found that the oxidation of magnetite particles follows a two-step kinetics phenomenon in parallel, which can be described by the Avrami kinetic model (AKM). The AKM describes the kinetics of isothermal phase transformation in materials, represented by Eq. [2]. The phase-transformation kinetics often follow a sigmoidal (S-shaped) profile with initial slow rates owing to the formation of a sufficient number of nuclei (nucleation). Thereafter, the rate increases at a rapid rate as the nuclei grow into particles (growth) and cease slowly when complete transformation is approached. ${ }^{[24,25]}$

$$
f=\left(1-e^{-a t^{n}}\right),
$$

where $f$ is the conversion or transformation that is achieved in isothermal $t$, and the coefficients of the AKM are $a$, the rate constant, and $n$, the time exponent that provides insight into the type of nucleation and growth mechanism.

The isothermal oxidation mechanisms for LKAB's magnetite concentrate have been investigated experimentally to estimate the kinetic parameters. Isothermal experiments were performed by considering three main parameters as variables, namely, temperature $[773 \mathrm{~K}$ to $1073 \mathrm{~K}\left(500{ }^{\circ} \mathrm{C}\right.$ to $\left.800{ }^{\circ} \mathrm{C}\right)$ ], the partial pressure of oxygen in the oxidizing gas ( 0.05 to $0.21 \mathrm{~atm})$, and an average concentrate particle size ( 45.5 to $68.5 \mu \mathrm{m}$ ). The results were analyzed with the two kinetic models, SCM and AKM, and compared with the experimental observations to identify the oxidation mechanisms. The non-isothermal behavior was validated by performing non-isothermal experiments.

Isothermal thermogravimetric analysis (TGA) studies can be conducted in two ways: (1) by allowing the sample to reach the isothermal temperature in an inert gas atmosphere and then switching from an inert to a reactive gas ${ }^{[7,9,22]}$ and (2) by inserting the sample for a short duration into the reactor zone at a desired temperature and gas composition. ${ }^{[2]}$ Both methods exhibit disadvantages in terms of initial transients. In the former method, depending on the reactor volume and gas flow rates, it would take some time for the gas composition to reach a stable value. In the latter case, 
depending on the thermal capacity of the crucible and the sample, time is required for the crucible-sample assembly to reach the desired steady temperature. Most experiments reported in the literature have used the former method. In this study, the latter method has been chosen.

\section{METHODS AND MATERIALS}

\section{A. Raw Materials}

The magnetite concentrate was from LKAB's mine in Malmberget, Sweden. The concentrate was collected carefully by coning and quartering and contained 96.32 pct $\mathrm{Fe}_{3} \mathrm{O}_{4}, 0.4$ pct $\mathrm{SiO}_{2}$, and 0.23 pct $\mathrm{Al}_{2} \mathrm{O}_{3}$ with minor proportions of $\mathrm{CaO}, \mathrm{MgO}, \mathrm{MnO}$, and $\mathrm{TiO}_{2}$. The concentrate is wet-sieved into three narrow size fractions, 38 to $53 \mu \mathrm{m}$ (mesh \#400), 53 to $63 \mu \mathrm{m}$ (mesh \#270), and 63 to $74 \mu \mathrm{m}$ (mesh \#230), with average particle diameters $\left(d_{\mathrm{p}}\right)$ of $45.5,58$, and $68.5 \mu \mathrm{m}$, respectively. This enabled us to capture the effect of particle size on the inherent oxidation behavior. The sieved concentrates were collected and dried in an oven at $423 \mathrm{~K}\left(150^{\circ} \mathrm{C}\right)$ overnight. Thereafter, to ensure the efficiency of sieving, the particle-size distribution of the sieved particles was determined by a laser-based method (CILAS 1190, France).

\section{B. Oxidation Experiments}

Isothermal oxidation of the magnetite particles was studied using TGA (Setaram 92, Setaram, France). The TGA consisted of a platinum crucible that was suspended from a weighing balance at the top and lowered into a graphite tube furnace with the assistance of an elevator, as shown in Figure 1.

Approximately $27 \mathrm{mg}$ of a narrow size fraction of particles $\left(d_{\mathrm{p}}\right)$ was poured into a platinum crucible $(8 \mathrm{~mm}$ in diameter and $5 \mathrm{~mm}$ in depth) to form a shallow layer of approximately $2 \mathrm{~mm}$. An S-type thermocouple was placed beneath the sample to measure the temperature. Different proportions ( 5 to $21 \mathrm{pct}$ ) of oxygen in nitrogen were used as the oxidizing gas, mixed with the help of a digital gas mixer. The oxidizing gas was allowed to flow from the bottom to the top of the furnace at $200 \mathrm{ml} / \mathrm{min}$. This flow rate exceeded the optimized gas flow rate achieved by performing starvation tests to ensure that the resistance because of gas diffusion is negligible. The thermal excursion designed for each of the experiments comprises heating the furnace to the isothermal temperature at $20 \mathrm{~K} / \mathrm{min}$, holding it under isothermal conditions for $60 \mathrm{~min}$, followed by cooling at $20 \mathrm{~K} / \mathrm{min}$ under the desired oxidizing atmosphere. Once the gas atmosphere had been established and isothermal temperature had been reached, the sample was lowered into the furnace. It is reasonable to consider the non-isothermal oxidation while lowering the sample to be negligible, compared with the overall oxidation extent and time. Isothermal oxidation experiments were conducted over a range of temperature, $p_{\mathrm{O}_{2}}$ and size fraction as provided in Table I. Background correction tests were

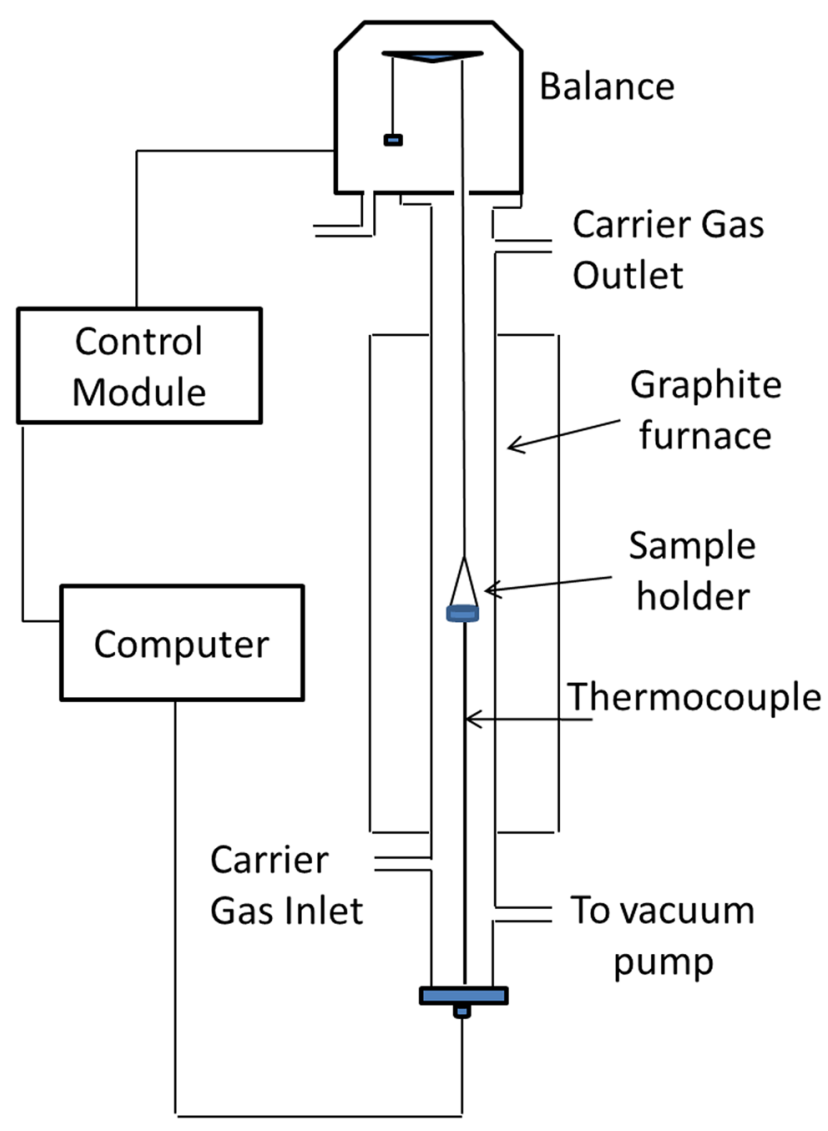

Fig. 1-Schematic of Setaram TG92-16 TGA.

conducted for each TGA experiment using an empty platinum crucible by following the respective thermal and gas profiles. The weight gain was captured every second by the data logger, corrected using the background tests, and then used for further analysis. Non-isothermal oxidation experiments were conducted at $20 \mathrm{~K} / \mathrm{min}$ from room temperature to the set isothermal temperature for $873 \mathrm{~K}$ to $1073 \mathrm{~K}\left(600{ }^{\circ} \mathrm{C}\right.$ to $\left.800{ }^{\circ} \mathrm{C}\right)$.

\section{Optical Microstructures}

The partially oxidized magnetite particles were cold mounted in epoxy, vacuum impregnated, and polished to a fineness of $1 \mu \mathrm{m}$ with diamond paste to obtain a flat reflecting surface for examination under the microscope. Microstructures were captured using a light optical microscope (Zeiss Imager.M2m, Germany) at a magnification of 1000 times to examine the pattern of the oxidation interface and hematite needle growth.

\section{RESULTS AND DISCUSSIONS}

\section{A. Oxidation Fraction and Oxidation Rate}

Magnetite oxidation is accompanied by weight gain. For the $\mathrm{Fe}_{3} \mathrm{O}_{4}$ content of the concentrate used, the theoretical or maximum weight-gain percentage $\left(\Delta W_{\max }\right)$ that the magnetite particles can achieve during 
Table I. Experimental Design for the Oxidation of Magnetite Particles in TGA

\begin{tabular}{|c|c|c|c|c|c|}
\hline & Particle Experiment & $T, \mathrm{~K}\left({ }^{\circ} \mathrm{C}\right)$ & $p_{\mathrm{O}_{2}}(\mathrm{~atm})$ & Size Fraction, $d_{\mathrm{p}}(\mu \mathrm{m})$ & H.R., $(\mathrm{K} / \mathrm{min})$ \\
\hline \multirow[t]{14}{*}{ Isothermal Oxidation } & $\mathrm{P} 1$ & $773(500)$ & 0.21 & 38 to 53 & - \\
\hline & $\mathrm{P} 2$ & $823(550)$ & 0.21 & 38 to 53 & - \\
\hline & P3 & $873(600)$ & 0.21 & 38 to 53 & - \\
\hline & P4 & $923(650)$ & 0.21 & 38 to 53 & - \\
\hline & P5 & $973(700)$ & 0.21 & 38 to 53 & - \\
\hline & P6 & $1023(750)$ & 0.21 & 38 to 53 & - \\
\hline & P7 & $1073(800)$ & 0.21 & 38 to 53 & - \\
\hline & P8 & $873(600)$ & 0.05 & 38 to 53 & - \\
\hline & P9 & $873(600)$ & 0.10 & 38 to 53 & - \\
\hline & P10 & $873(600)$ & 0.15 & 38 to 53 & - \\
\hline & P3 & $873(600)$ & 0.21 & 38 to 53 & - \\
\hline & P3 & $873(600)$ & 0.21 & 38 to 53 & - \\
\hline & P11 & $873(600)$ & 0.21 & 53 to 63 & - \\
\hline & P12 & $873(600)$ & 0.21 & 63 to 74 & - \\
\hline \multirow[t]{3}{*}{ Non-isothermal Oxidation } & $\mathrm{P} 13$ & $873(600)$ & 0.21 & 38 to 53 & 20 \\
\hline & P14 & $973(700)$ & 0.21 & 38 to 53 & 20 \\
\hline & P15 & $1073(800)$ & 0.21 & 38 to 53 & 20 \\
\hline
\end{tabular}

its oxidation to hematite was found to be 3.33 pct. The fraction of conversion during oxidation was normalized with respect to the theoretical weight gain. Therefore, the oxidation fraction $(f)$ or degree of oxidation was determined as the ratio of the weight gain captured by TGA to the maximum weight gain of the magnetite particles during oxidation according to Eq. [3]. Thereafter, the oxidation rate that corresponded to the oxidation fraction was calculated for the given thermal profile.

$$
f=\frac{\left(\frac{W_{\mathrm{f}}-W_{\mathrm{i}}}{W_{\mathrm{i}}}\right) \times 100}{\Delta W_{\max }}=\frac{\Delta W_{\mathrm{TGA}}}{\Delta W_{\max }},
$$

where $\Delta W_{\mathrm{TGA}}$ is the percentage weight change measured during oxidation in TGA between the initial $\left(W_{\mathrm{i}}\right)$ and final $\left(W_{\mathrm{f}}\right)$ particle weight.

The profiles of oxidation fraction and oxidation rate for the magnetite particles at different temperatures, the partial pressure of the oxidizing gas, and the particle size with respect to the isothermal time are shown in Figure 2 . The oxidation fraction increases initially at a rapid rate, and thereafter plateaus where the oxidation increases gradually at a constant oxidation rate. This implies that magnetite oxidation at the particle scale is a two-step phenomenon, which is in line with the findings reported by several researchers. ${ }^{[2,7,15,22,23]}$ The degree of oxidation (fraction) increases with isothermal temperature (Figure 2(a)) from $773 \mathrm{~K}$ to $1073 \mathrm{~K}\left(500{ }^{\circ} \mathrm{C}\right.$ to $800{ }^{\circ} \mathrm{C}$ ) and with increasing $p_{\mathrm{O}_{2}}$ in the oxidizing gas from 0.05 to 0.21 (Figure 2(b)). Finer particle-size fractions (Figure 2(c)) with a larger surface area achieve a higher degree of oxidation compared with relatively coarser particle-size fractions, in the order of 38 to $53 \mu \mathrm{m}$ $>53$ to $63 \mu \mathrm{m}>63$ to $74 \mu \mathrm{m}$. However, there is a marginal difference in the oxidation profiles for the two larger particle-size fractions. This could be because of the agglomeration of some of the finer particles onto the large particles observed by optical-microscopy analysis. This could be because of the limitations in the capability of available size-distribution techniques (wet-sieving) to separate very fine magnetite particles. The authors will aim to develop a quantitative analysis for size distribution by optical microscopy.

\section{B. Kinetic Models}

\section{SCM}

The isothermal oxidation results were analyzed using the SCM to evaluate the kinetics. According to the SCM, the conversion proceeds by mass transfer of the gaseous phase, chemical reaction, and solid-state diffusion kinetics, as mentioned in Eq. [2]. In general, the mass transfer of the oxidizing gas to the particle surface is not rate limiting, even when the gas flow rate is optimized with the help of starvation tests in TGA. If the chemical reaction is the dominant step, the fraction of conversion for the spherical particles with respect to time proceeds according to Eq. [4], whereas, if diffusion through the product layer is the rate-controlling mechanism, the same is represented by Eq. [5]. ${ }^{[21,22]}$

Chemical reaction at the interface,

$$
F_{\mathrm{R}}=\left[1-(1-f)^{\left(\frac{1}{3}\right)}\right]=k_{\mathrm{R}} t_{\mathrm{R}}
$$

$$
\begin{aligned}
& \text { Diffusion through the product layer, } \\
& \qquad F_{\mathrm{S}}=\left[3-2 f-3(1-f)^{\left(\frac{2}{3}\right)}\right]=k_{\mathrm{S}} t_{\mathrm{S}},
\end{aligned}
$$

where $F_{\mathrm{R}}$ and $F_{\mathrm{S}}$ are conversion fractions that correspond to chemical reactions and diffusion in the isothermal time $t_{\mathrm{R}}$ and $t_{\mathrm{S}}$ with the rate constants $k_{\mathrm{R}}$ and $k_{\mathrm{S}}$, respectively. 

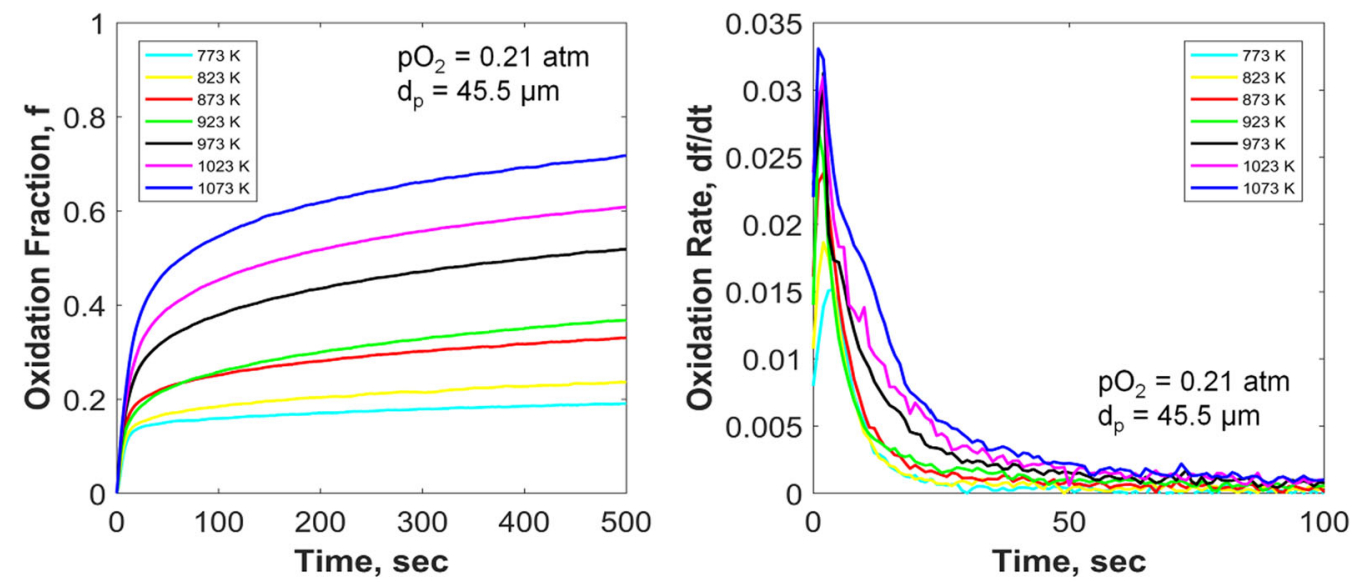

(a)
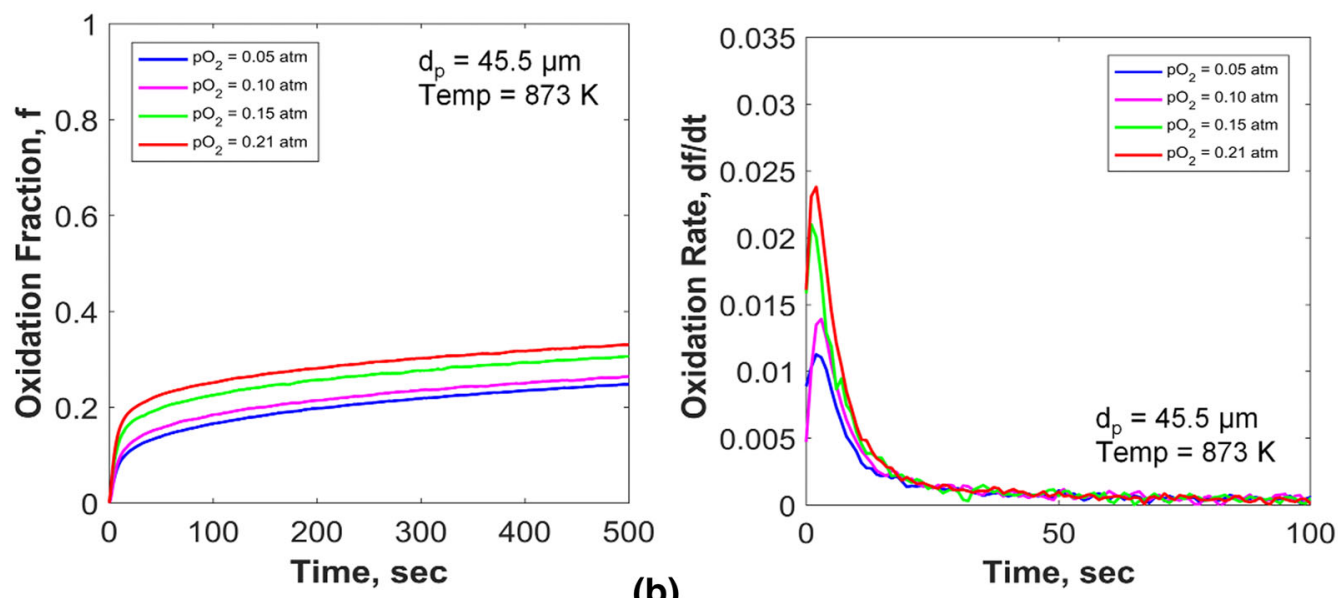

(b)
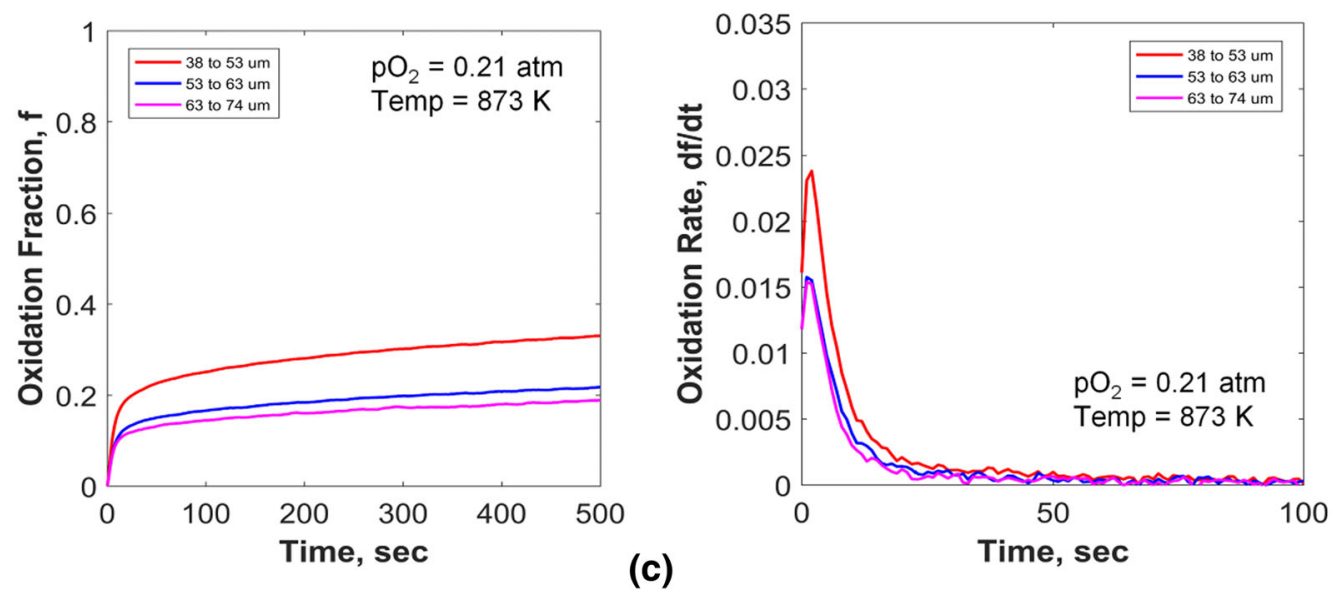

Fig. 2 - Oxidation fraction and oxidation rate for magnetite particles with respect to $(a)$ isothermal temperatures, $(b) p_{\mathrm{O}_{2}}$ in oxidizing gas, and $(c)$ size fraction.

The oxidation fraction $(f)$ of magnetite particles as obtained experimentally for different isothermal temperatures has been rearranged and plotted according to Eqs. [5] and [6] with respect to the isothermal time, respectively, as shown in Figure 3 . The conversion-time plots for the initial oxidation (Figure 3(a)) and the later stages (Figure 3(b)) fit a straight-line equation. This implies that the oxidation of magnetite particles proceeds by the SCM and is initially dominated by chemical reaction and thereafter by diffusion through the hematite product layer. The slopes of the curves that fit Eqs. [4] and [5] determine the rate-constant terms $\left(k_{\mathrm{R}}\right.$ and $\left.k_{\mathrm{S}}\right)$, respectively. 

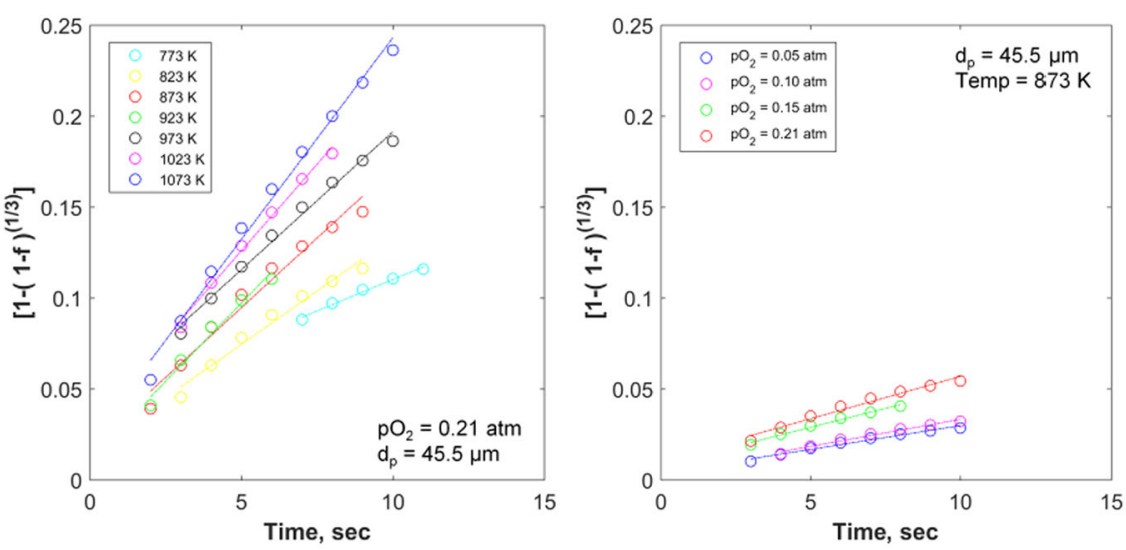

(a)
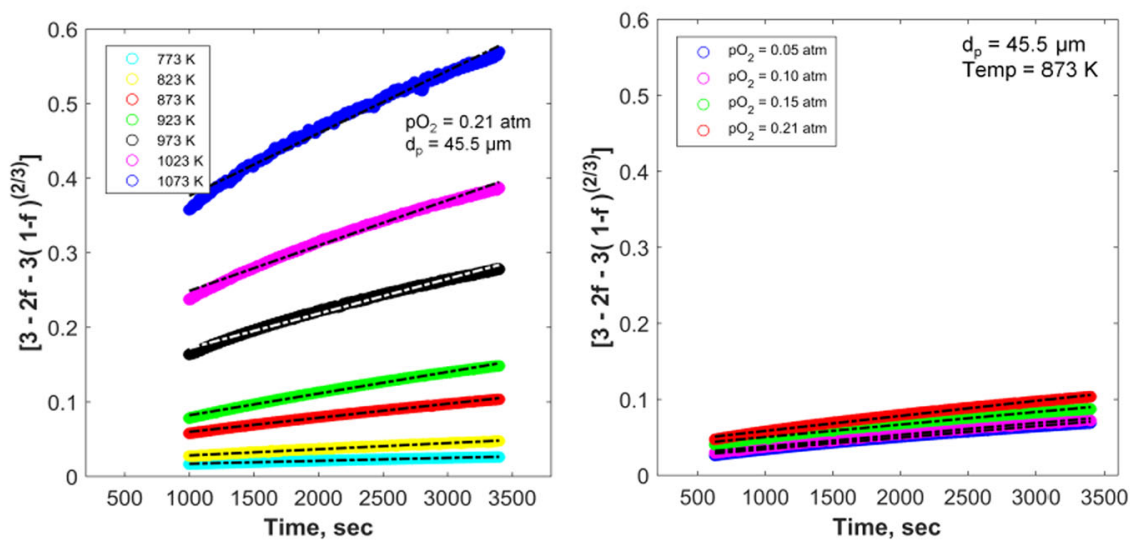

(b)
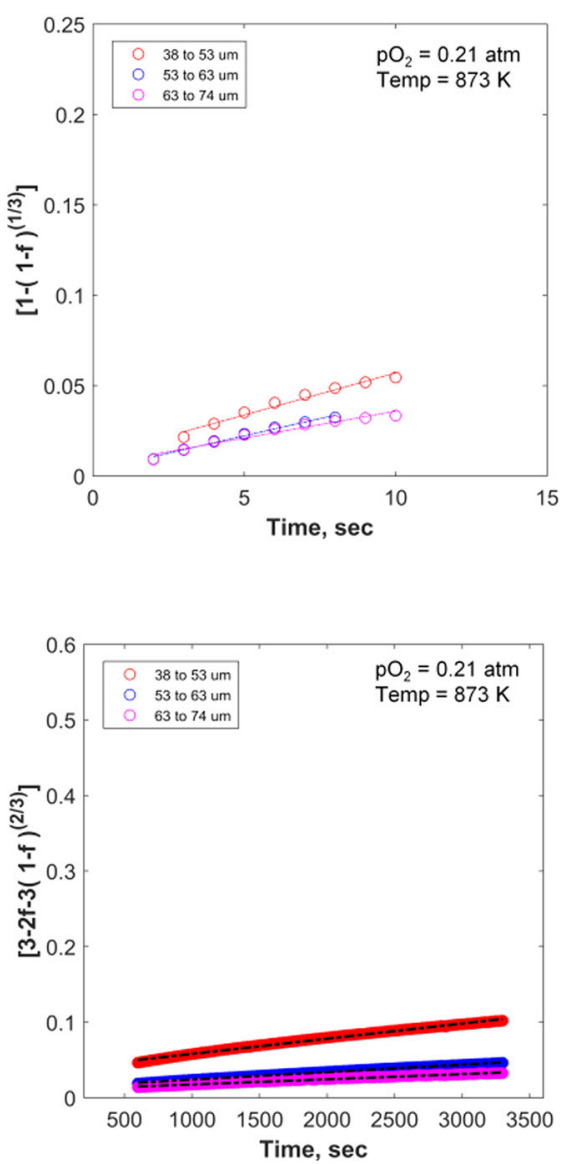

Fig. 3-Isothermal oxidation by SCM with respect to different isothermal temperatures, $p_{\mathrm{O}_{2}}$, and size fraction with $(a)$ chemical reaction and $(b)$ diffusion as dominant mechanisms.

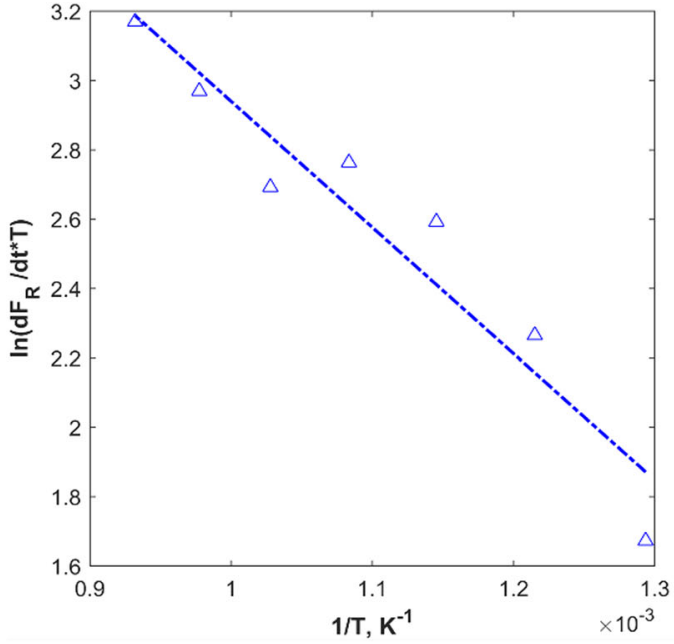

(a)

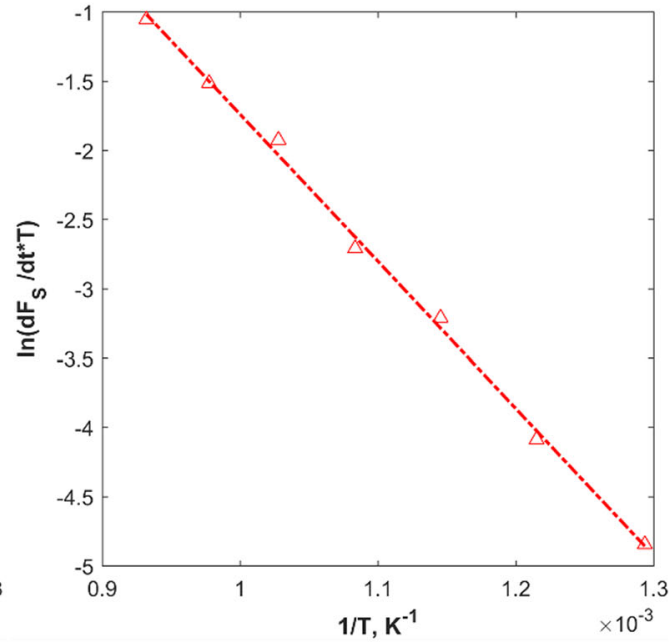

(b)

Fig. 4-Arrhenius equation plots to estimate activation energy for $(a)$ chemical reaction and $(b)$ solid-state diffusion-controlling mechanism. 
Because oxidation is a thermally activated phenomenon, the variation in rate constant with respect to the isothermal temperature is expressed by the Arrhenius equation (Eq. [6]) and is plotted as shown in Figure 4 for each of the mechanisms independently.

$$
\ln \left(T K^{(1 / n)}\right)=\ln K_{0}-\frac{Q}{R T},
$$

where $n$ is the time exponent, $Q$ is the activation energy $(\mathrm{J} / \mathrm{mol}), K$ is the rate constant $\left(\mathrm{s}^{-1}\right)$ of the dominant mechanism, $K_{0}$ is the pre-exponential factor $\left(\mathrm{s}^{-1}\right)$ for the first-order reaction, $T$ is the temperature in $\mathrm{K}$, and $R$ is the gas constant in $\mathrm{J} / \mathrm{mol} / \mathrm{K}$.

The respective slope and intercept of Eq. [6] determines the activation energies and pre-exponential factor. The activation energies for the initial and later stages of the magnetite-particle oxidation were found to be 31 and $76.5 \mathrm{~kJ} / \mathrm{mol}$, respectively. This implies that the oxidation of magnetite particles at the initial stage may not only occur because of the chemical reaction. Instead, it can be postulated that the initial oxidation is dominated by the mixed influence of gas-phase mass transfer and chemical reaction, whereas, during the later stages, oxidation proceeds by diffusion.

\section{2. $A K M$}

The AKM hypothesizes that the isothermal conversion or phase transformation of particles proceeds by nucleation and growth, represented by Eq. [2]. The results for the isothermal oxidation from experiments on magnetite concentrate have been analyzed with the AKM by rearranging Eq. [2] to a straight line as shown in Eq. [7]. The isothermal oxidation results plotted according to Eq. [7] with respect to time for magnetite particles exposed to different temperatures, $p_{\mathrm{O}_{2}}$ and size fraction are shown in Figure 5.

$$
(\ln (-\ln (1-f)))=n \ln (t)+\ln (a),
$$

Two straight lines with different slopes for the initial and later stages of oxidation result for the experiments with all variables. This result implies that the isothermal oxidation of magnetite concentrate investigated in this study satisfies the AKM. The Avrami rate constant (a) for different isothermal experiments is related to the Arrhenius rate constant $(K)$ according to Eq. [8]. Thereafter, the Arrhenius Equation (Eq. [6]) is plotted for the nucleation and growth mechanisms, as shown in Figure 6, to estimate activation energies $(Q)$ and pre-exponential factors $\left(K_{0}\right)$ by evaluating the respective slopes and intercepts.

$$
K=a^{\frac{1}{n}} .
$$

The activation energies that were estimated for the nucleation and growth mechanisms are 15 and 226 $\mathrm{kJ} / \mathrm{mol}$, respectively. Therefore, it can be postulated that during oxidation, hematite $\left(\mathrm{Fe}_{2} \mathrm{O}_{3}\right)$ needles grow by solid-state diffusion of oxygen anions into a matrix of magnetite $\left(\mathrm{Fe}_{3} \mathrm{O}_{4}\right)$ particles. ${ }^{[23]}$ Some uncertainties may exist during the first few seconds of the initial stage because too few data points exist and too little stabilization of experimental data occurs or because of a response of the weighing balance to the weight gain. Therefore, further analysis was focused primarily on the later stage of the oxidation reaction to determine the kinetics.

The pre-exponential factor $\left(K_{0}\right)$ and time exponent $(n)$ determined from the Arrhenius equation (Eq. [6]) and the slopes of Eq. [7], respectively, are tabulated in Table II. The pre-exponential factor $\left(K_{0}\right)$ is found to vary with $p_{\mathrm{O}_{2}}$ and $d_{p}$ according to Eqs. [9] and [10], respectively. The time exponent $(n)$ increases linearly with respect to the temperature, and decreases with $p_{\mathrm{O}_{2}}$ in the oxidizing gas as per Eqs. [11] and [12], respectively, whereas it does not vary with the particle-size fraction.

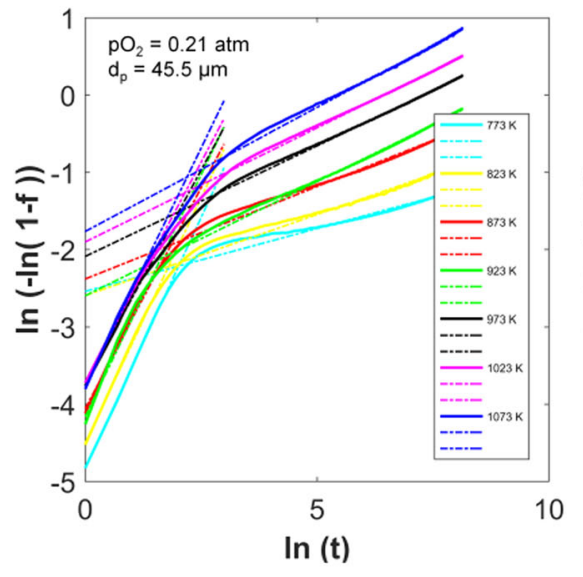

(a)

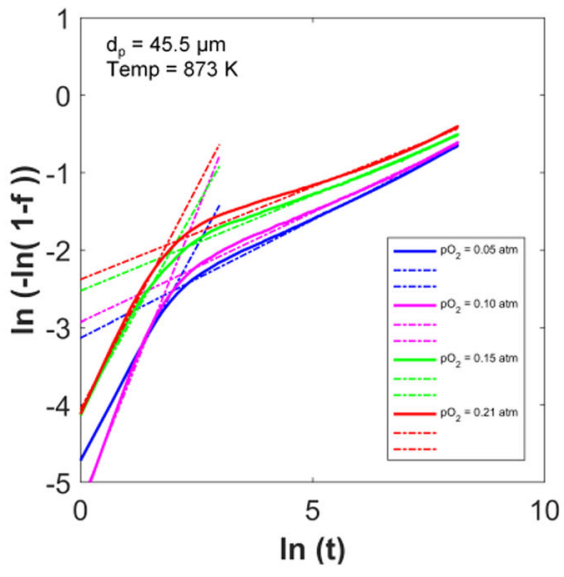

(b)

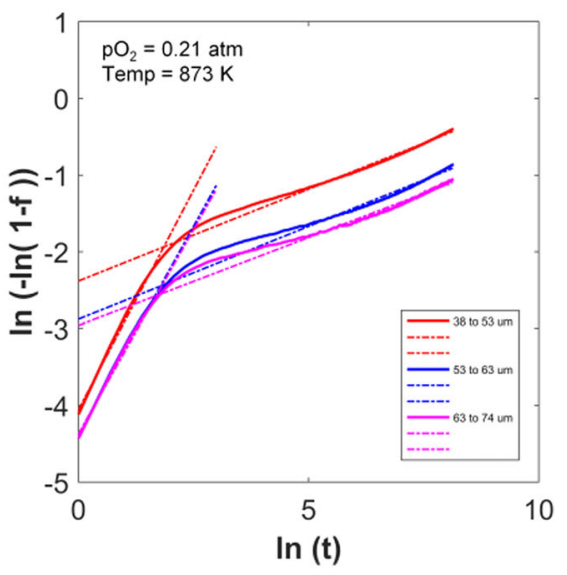

(c)

Fig. 5-Isothermal oxidation by AKM for different (a) isothermal temperatures, $(b) p_{\mathrm{O}_{2}}$, and (c) size fractions. 


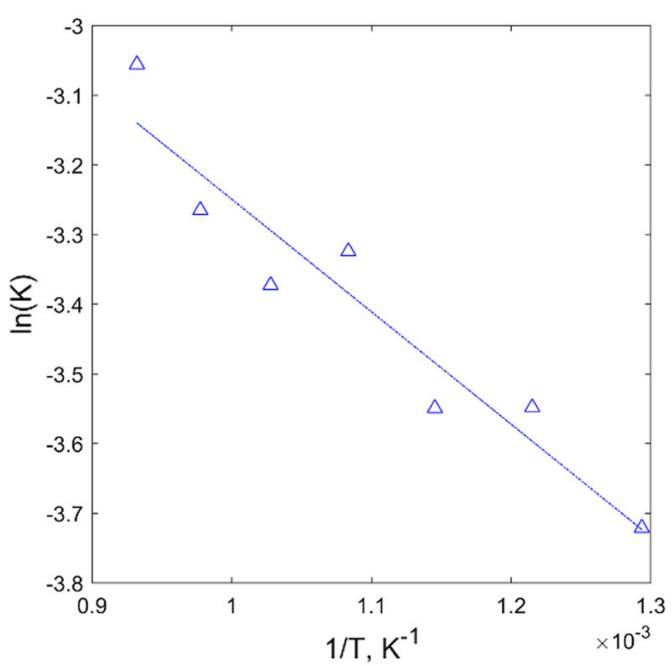

(a)

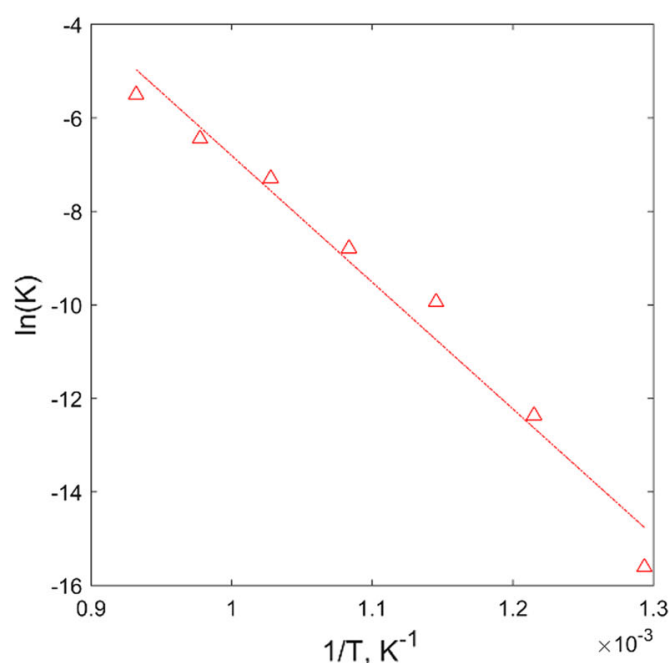

(b)

Fig. 6-Arrhenius plots for AKM for (a) nucleation and (b) growth mechanisms during oxidation of magnetite concentrate.

Table II. Pre-exponential $\left(K_{0}\right)$ and Time Exponent $(n)$ Determined by AKM for Magnetite-Particle Oxidation Experiments

\begin{tabular}{|c|c|c|c|c|c|}
\hline Particle Experiment & $T, \mathrm{~K}\left({ }^{\circ} \mathrm{C}\right)$ & $p_{\mathrm{O}_{2}}(\mathrm{~atm})$ & Size Fraction, $d_{\mathrm{p}}(\mu \mathrm{m})$ & $K_{0} \times 10^{8}\left(\mathrm{~s}^{-1}\right)$ & $n$ \\
\hline P1 & $773(500)$ & 0.21 & 38 to 53 & \multirow[t]{3}{*}{6.3} & 0.16 \\
\hline $\mathrm{P} 2$ & $823(550)$ & 0.21 & 38 to 53 & & 0.21 \\
\hline P3 & $873(600)$ & 0.21 & 38 to 53 & & 0.23 \\
\hline $\mathrm{P} 4$ & $923(650)$ & 0.21 & 38 to 53 & \multirow[t]{4}{*}{$\mathrm{CI}=(1.9,21.3)$} & 0.29 \\
\hline P5 & $973(700)$ & 0.21 & 38 to 53 & & 0.28 \\
\hline P6 & $1023(750)$ & 0.21 & 38 to 53 & & 0.29 \\
\hline P7 & $1073(800)$ & 0.21 & 38 to 53 & & 0.32 \\
\hline P8 & $873(600)$ & 0.05 & 38 to 53 & 9.9 & 0.30 \\
\hline P9 & $873(600)$ & 0.10 & 38 to 53 & 9.4 & 0.28 \\
\hline $\mathrm{P} 10$ & $873(600)$ & 0.15 & 38 to 53 & 10.6 & 0.24 \\
\hline P3 & $873(600)$ & 0.21 & 38 to 53 & 14.3 & 0.23 \\
\hline P3 & $873(600)$ & 0.21 & 38 to 53 & 14.3 & 0.23 \\
\hline P11 & $873(600)$ & 0.21 & 53 to 63 & 2.0 & 0.24 \\
\hline $\mathrm{P} 12$ & $873(600)$ & 0.21 & 63 to 74 & 0.7 & 0.22 \\
\hline
\end{tabular}

$$
\begin{gathered}
K_{0}=2.81 \times 10^{9} p_{\mathrm{O}_{2}}+7.511 \times 10^{8} \\
K_{0}=-6.054 \times 10^{13} d_{p}+4.024 \times 10^{9} \\
n=4.938 \times 10^{-4} T-0.197 \\
n=-0.428 p_{\mathrm{O}_{2}}+0.3231 .
\end{gathered}
$$

\section{Predicting Isothermal Oxidation-Comparison Between SCM and AKM}

The derived kinetic parameters have been used to predict the isothermal oxidation behavior of the magnetite concentrate. The oxidation fraction of the concentrate is predicted according to the SCM and AKM kinetic models using Eq. [1] for the SCM (assuming mass transfer is not rate limiting) and Eq. [2] for the AKM. The predicted profiles of the oxidation fraction $(f)$ for different isothermal temperatures with respect to time are validated with the respective experimental behavior, as shown in Figure 7. 


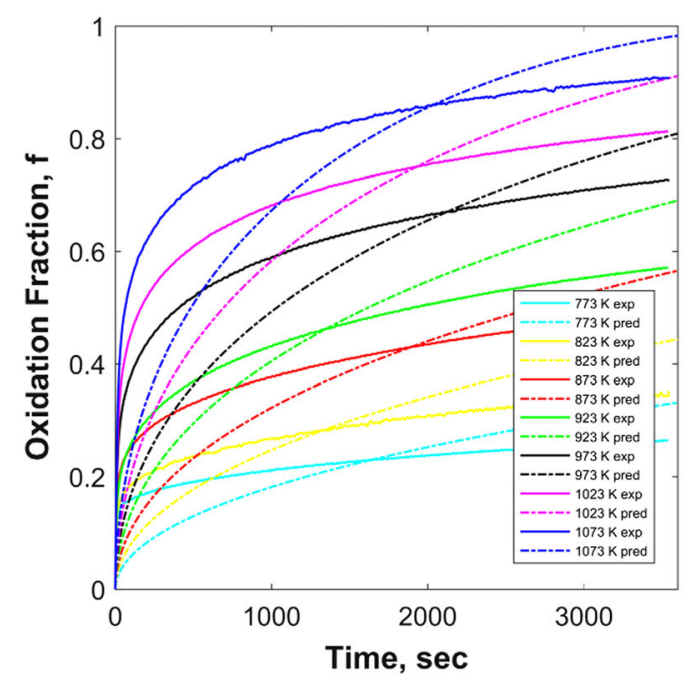

(a)

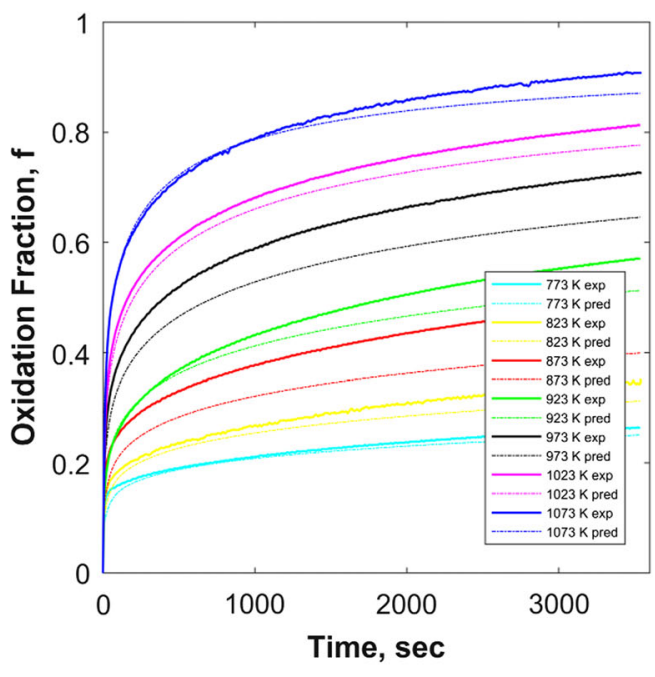

(b)

Fig. 7-Predicted and experimental isothermal oxidation of magnetite concentrate $\left(38\right.$ to $53 \mu \mathrm{m}$ at $p_{\mathrm{O}_{2}}=0.21 \mathrm{~atm}$ atm according to $(a)$ the $\mathrm{SCM}$ and $(b)$ the AKM.

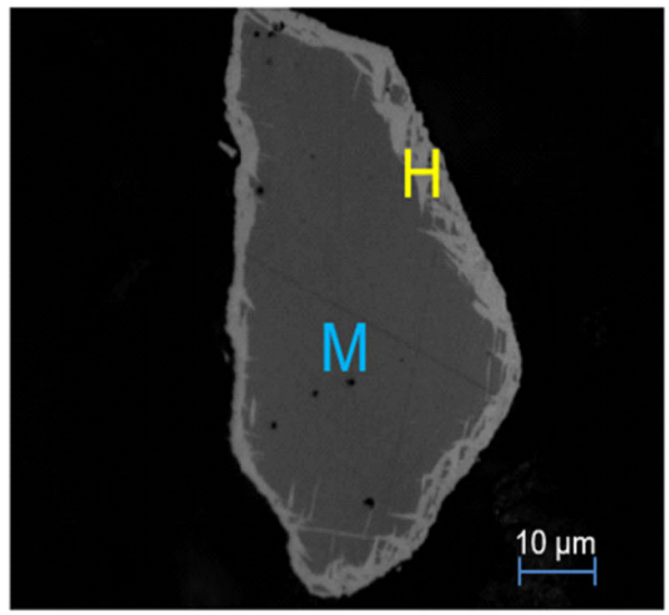

(a)

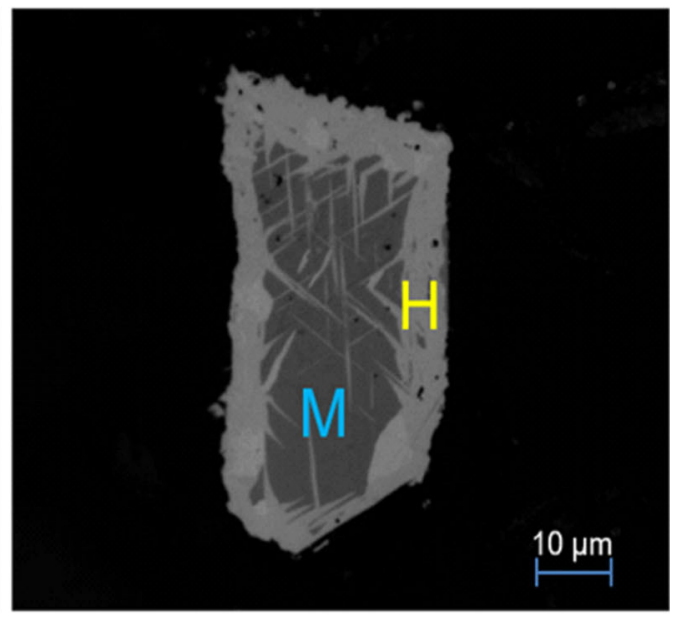

(b)

Fig. 8-Light optical microstructures (1000 times magnification) of magnetite particles (38 to $53 \mu \mathrm{m})$ oxidized at an isothermal temperature of (a) $873 \mathrm{~K}\left(600^{\circ} \mathrm{C}\right)$ and $(b) 1073 \mathrm{~K}\left(800^{\circ} \mathrm{C}\right)$ showing hematite needles $(\mathrm{H})$ growing into the magnetite matrix $(\mathrm{M})$.

The oxidation profiles that are predicted from the AKM (Figure 7(b)) agree significantly better with the experimental observations compared with those predicted from the SCM (Figure 7(a)). Optical microstructures of magnetite particles ( 38 to $53 \mu \mathrm{m}$ ) that were oxidized at isothermal temperatures of $873 \mathrm{~K}$ and 1073 $\mathrm{K}\left(600{ }^{\circ} \mathrm{C}\right.$ and $\left.800{ }^{\circ} \mathrm{C}\right)$ for $60 \mathrm{~min}$ were examined, as shown in Figure 8. The oxidation proceeds inwards from the magnetite-particle surface by nucleation of needle-like hematite crystals that begin to grow along the preferred planes in the magnetite at the lower temperature $\left[873 \mathrm{~K}\left(600{ }^{\circ} \mathrm{C}\right)\right]$. Similar findings have been observed by Monazam et al. ${ }^{[23]}$ As the extent or fraction of oxidation increases at higher temperature $\left[1073 \mathrm{~K}\left(800^{\circ} \mathrm{C}\right)\right]$, a sharp reaction interface appears that progresses inwards somewhat in an anisotropic manner, albeit with hematite needles that grow significantly ahead of the reaction interface into the magnetite-particle matrix. A similar observation was reported by Monsen et al. ${ }^{[15]}$ Thus, it can be substantiated that magnetite-particle oxidation considered in this study proceeds by nucleation and growth, where hematite needle growth into the magnetite particles occurs via a solid-state diffusion mechanism. These findings are also consistent for particles exposed to different $p_{\mathrm{O}_{2}}$ and $d_{\mathrm{p}}$.

The activation energy estimated by the SCM in this study for the diffusion stage is $76.1 \mathrm{~kJ} / \mathrm{mol}$. Activation energies in a similar range were found by $\mathrm{Cho}^{[22]}$ using the SCM. The lower activation energies for the solid-state diffusion is attributed to a short-circuit path or grain-boundary diffusion. Significantly higher 
activation energies, such as 242, 208, and $469 \mathrm{~kJ} / \mathrm{mol}$, have been reported by Himmel, ${ }^{[26]}$ Päidassi, ${ }^{[27]}$ and Davies, ${ }^{[2]}$ respectively, for the solid-state diffusion mechanism. However, the activation energy determined by the AKM for the growth stage was $226 \mathrm{~kJ} / \mathrm{mol}$, which falls in the range of values reported in the literature. ${ }^{[26-28]}$ This result is backed up by the predicted profiles for the oxidation fraction by the AKM, which matches that obtained experimentally fairly well (Figure 7), as well as by the microstructural observation of hematite crystal growth ahead of the reaction interface (Figure 8). Therefore, for the activation-energy values, predicted oxidation profiles, and microstructural observations, the AKM describes the oxidation mechanisms of the magnetite concentrate suitably. Hence, AKM was used to predict the oxidation behavior of the magnetite concentrate.

\section{Non-isothermal Oxidation Prediction Using Kinetic Parameters}

In industrial operations, magnetite-particle pellets are exposed to non-isothermal atmospheres, and therefore it is appropriate to predict the non-isothermal oxidation behavior of the magnetite concentrate investigated in this study. The kinetic parameters derived from isothermal studies using AKM were extended to predict the non-isothermal oxidation behavior of the magnetite concentrate. This has been done by discretizing the entire non-isothermal (time-temperature) plot with several small pseudo-isothermal steps. The variation in oxidation fraction $(f)$ can be obtained from the temporal variation of temperature and the corresponding Avrami coefficients $(a, n)$, using Eq. [2] by proceeding in time for a sufficiently small $\Delta \mathrm{t}$.

To develop the oxidation model that should be able to consider all three parameters as variables, the kinetic parameters $\left(n, K_{0}\right)$ have been correlated with $T, p_{\mathrm{O}_{2}}$, and $d_{\mathrm{p}}$ to have a combined effect in the range considered in this study. The time exponent $(n)$ is a function of $T$ and $p_{\mathrm{O}_{2}}$, whereas the pre-exponential factor $\left(K_{0}\right)$ is dependent on $p_{\mathrm{O}_{2}}$ and $d_{\mathrm{p}}$. These coefficients are correlated to their parameters in a bilinear way using the least-squares fitting method according to Eqs. [13] and [14], respectively.

$$
\begin{aligned}
n= & 1.76 \times 10^{-4} T+0.1255 \ln \left(p_{\mathrm{O}_{2}}\right)-2.03 \times 10^{-4} T \\
& \cdot \ln \left(p_{\mathrm{O}_{2}}\right)
\end{aligned}
$$

$$
\log _{10} K_{0}=11.46+0.786 p_{\mathrm{O}_{2}}-5.55 \times 10^{-4} d_{\mathrm{p}} .
$$

These predictions have been validated by the non-isothermal oxidation experiments. The magnetite concentrate in the size fraction of 38 to $53 \mu \mathrm{m}$ $\left(d_{\mathrm{p}}=45.5 \mu \mathrm{m}\right)$ was oxidized non-isothermally from room temperature to different isothermal temperatures [ $873 \mathrm{~K}, 973 \mathrm{~K}$ and $1073 \mathrm{~K}\left(600^{\circ} \mathrm{C}, 700^{\circ} \mathrm{C}\right.$ and $\left.800{ }^{\circ} \mathrm{C}\right)$ ] at $20 \mathrm{~K} / \mathrm{min}$ with 21 pct oxygen in the oxidizing gas

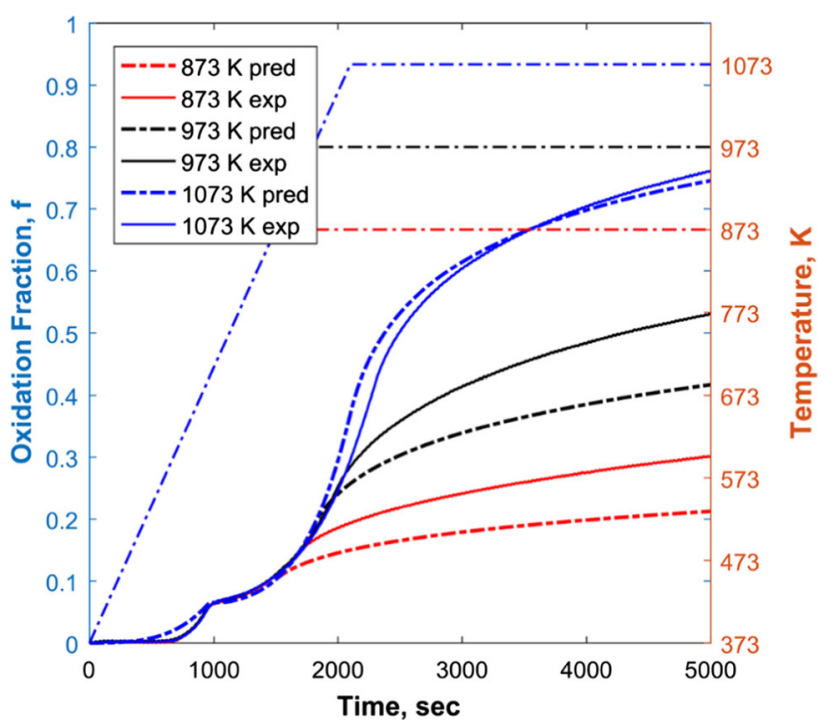

Fig. 9-Prediction and validation of non-isothermal oxidation for magnetite concentrate ( 38 to $53 \mu \mathrm{m}$ ) at $p_{\mathrm{O}_{2}}=0.21 \mathrm{~atm}$ by adapting the AKM.

$\left(p_{\mathrm{O}_{2}}=0.21 \mathrm{~atm}\right)$ at $200 \mathrm{ml} / \mathrm{min}$. The predicted non-isothermal oxidation profiles have been plotted with the experimental profiles for validation in Figure 9.

A kink exists in Figure 9 at approximately $f=0.55$ to 0.65 pct and $723 \mathrm{~K}\left(450{ }^{\circ} \mathrm{C}\right)$. Similar observations have been reported earlier, ${ }^{[2,13,29,30]}$ and it has been postulated that this occurs because of the formation of $\gamma-\mathrm{Fe}_{2} \mathrm{O}_{3}$ (maghemite) at lower temperature, and further to $\alpha-\mathrm{Fe}_{2} \mathrm{O}_{3}$ (hematite) at a higher temperature $(\sim 873 \mathrm{~K}$ $\left(600{ }^{\circ} \mathrm{C}\right)$. However, the metastable nature of $\gamma-\mathrm{Fe}_{2} \mathrm{O}_{3}$ makes it difficult to confirm by characterization. The predicted oxidation profiles follow the experimental oxidation profiles with respect to the pattern or progress of the oxidation curves. It can also be inferred that a slight deviation from the model predictions results with regard to the absolute extent of oxidation fraction. The values of $n$ and $K^{\prime}$ that affect the oxidation behavior significantly have been fine-tuned to estimate the range where predictions are accepted statistically. An optimization of these by a least-squares fit enables us to generate non-isothermal oxidation predictions for entire thermal profiles within a 90 pct confidence interval.

Deviations from the experimental observations could be attributed to the fact that the particle shape within each narrow size fraction is not uniform and spherical. Another limitation could be the lack of experiments at different temperatures for the range of $p_{\mathrm{O}_{2}}$ and size fractions while determining the kinetic parameters. Although these experiments were not within the scope of this study, their incorporation will increase the window of experimental observations, which could improve the model efficiency, and can be considered in future studies. Further, the particle kinetics model developed in this study will be used to upscale and develop the oxidation model for magnetite at the pellet 
scale. This is communicated separately, and provides the overall oxidation behavior of magnetite at the pellet and particle scale.

\section{CONCLUSIONS}

The oxidation behavior of magnetite has been investigated quantitatively at the particle scale using TGA. The study focused on narrow size fractions of magnetite. Isothermal oxidation kinetics have been determined experimentally by considering the isothermal temperature, the partial pressure of oxygen in an oxidizing gas, and the particle-size fraction as variables. Experimental results were analyzed by two kinetic models, namely, the SCM and the AKM. The isothermal oxidation of the magnetite concentrate was predicted and validated for both kinetic models. Oxidation of the magnetite concentrate was described best by the AKM, which postulates that oxidation at the particle scale proceeds by nucleation and growth in the initial and later stages, respectively, where growth occurs by diffusion mechanisms. A methodology has been developed to predict the oxidation behavior of magnetite concentrate under non-isothermal conditions and validated experimentally.

\section{ACKNOWLEDGMENTS}

The authors thank the Hjalmar Lundbohm Research Centre (HLRC) for their financial support. We also thank Ola Eriksson and Daniel Marjavaara from LKAB for their technical input. The authors would also like to extend their sincere thanks to Professor N. B. Ballal and Professor M. P. Gururajan of the Indian Institute of Technology (IIT) Bombay for valuable discussions.

\section{OPEN ACCESS}

This article is distributed under the terms of the Creative Commons Attribution 4.0 International License (http://creativecommons.org/licenses/by/4.0/), which permits unrestricted use, distribution, and reproduction in any medium, provided you give appropriate credit to the original author(s) and the source, provide a link to the Creative Commons license, and indicate if changes were made.

\section{LIST OF SYMBOLS}

$\begin{array}{ll}k_{\mathrm{m}} & \text { Rate constant for mass transfer of gas } \\ k_{\mathrm{R}} & \begin{array}{l}\text { Rate constant for chemical reaction at the } \\ \text { interface }\end{array} \\ k_{\mathrm{S}} & \begin{array}{l}\text { Rate constant for diffusion } \\ D_{\mathrm{eS}}\end{array} \\ r & \begin{array}{l}\text { Diffusivity } \\ \text { Average radius of particles in the concentrate }\end{array}\end{array}$

$d_{\mathrm{p}} \quad$ Average diameter of particles in the concentrate

$p_{\mathrm{O}_{2}} \quad$ Partial pressure of oxygen in oxidizing gas

$T \quad$ Isothermal temperature

$W_{\mathrm{i}} \quad$ Initial weight of concentrate in TGA

$W_{\mathrm{f}} \quad$ Final weight of concentrate in TGA

$\Delta W_{\text {TGA }}$ Weight change during oxidation in TGA

$f \quad$ Fraction of concentrate conversion by oxidation

$C \quad$ Concentration of oxidizing gas in the pellet

$M \quad$ Molar mass

$\rho_{\mathrm{B}} \quad$ Bulk density

$t \quad$ Isothermal time

a Avrami rate constant

$n \quad$ Time exponent

$F_{\mathrm{R}} \quad$ Fraction of conversion because of chemical reaction at the interface

$F_{\mathrm{S}} \quad$ Fraction of conversion because of diffusion

$t_{\mathrm{R}} \quad$ Isothermal time to reach $F_{\mathrm{R}}$

$t_{\mathrm{S}} \quad$ Isothermal time to reach $F_{\mathrm{S}}$

$K \quad$ Arrhenius reaction rate constant

$K_{0} \quad$ Pre-exponential factor

$Q \quad$ Activation energy

$R \quad$ Ideal gas constant

\section{REFERENCES}

1. S. Forsmo: Ph.D. Thesis, Lulea University of Technology, Sweden, 2007.

2. S.P.E. Forsmo, S. Forsmo, P. Samskog, and B.M.T. Björkman: Powder Technol., 2008, vol. 183, pp. 247-59.

3. T.K. Sandeep Kumar, N.N. Viswanathan, H.M. Ahmed, C. Andersson, and B. Björkman: Metall. Mater. Trans. B, 2015, vol. 46B, pp. 635-43.

4. T.K. Sandeep Kumar, N.N. Viswanathan, H.M. Ahmed, C. Andersson, and B. Björkman: Metall. Mater. Trans. B, 2016, vol. 47B, pp. 309-19.

5. J.D. Zetterstrom: Bureau of Mines Report of Investigations 4728, United States Department of the Interior, 1950.

6. J. Edström: Jernkontorets Ann, 1957, vol. 141, pp. 457-78.

7. H.J. Cho, M. Tang, and P.C. Pistorius: Metall. Mater. Trans. B, 2014, vol. 45B, pp. 1213-20.

8. Y. Huang, G. Han, T. Jiang, Y. Zhang, and G. Li: Miner. Process. Extr. Metall. Rev., 2013, vol. 34, pp. 42-56.

9. M Tang, HJ Cho, and PC Pistorius: Metall. Mater. Trans. B, 2014, vol. 45B, pp. 1304-14.

10. H.J. Cho and P.C. Pistorius: AISTech-Iron and Steel Technology Conference Proceedings, 2011, pp. 507-14.

11. P. Semberg, A. Rutqvist, C. Andersson, and B. Björkman: Ironmak. Steelmak., 2011, vol. 38, pp. 321-28.

12. J.R. Wynnyckyj and W.A. McCurdy: Metall. Trans., 1974, vol. 5, pp. 2207-15.

13. D. Papanastassiou and G. Bitsianes: Metall. Trans., 1973, vol. 4, pp. 487-96.

14. B.E. Monsen: Ph.D. Thesis, The Norwegian Institute of Technology, Norway, 1992.

15. B. Monsen, S. Olsen, and L. Kolbeinsen: Scand. J. Metall., 1994, vol. 23, pp. 74-80.

16. H.Y. Sohn and J. Szekely: Chem. Eng. Sci., 1972, vol. 27, pp. 76378.

17. J. Szekely, C.I. Lin, and H.Y. Sohn: Chem. Eng. Sci., 1973, vol. 28, pp. $1975-89$.

18. J. Szekely and H.Y. Sohn: Trans. Inst. Min. Metall. Sect. C Miner. Process. Extract. Metall., 1973, vol. 82, pp. c92-c100.

19. H. Sohn: Metall. Mater. Trans. B, 1978, vol. 9B, pp. 89-96.

20. D. Papanastassiou and G. Bitsianes: Metall. Trans., 1973, vol. 4, pp. $477-86$. 
21. L. Doraiswamy and M. Sharma: Heterogeneous Reactions-Analysis, Examples, and Reactor Design, Wiley, New York, 1984.

22. H.J. Cho: Ph.D. Thesis, Carnegie Mellon University, United States of America, 2012.

23. E.R. Monazam, R.W. Breault, and R. Siriwardane: Ind. Eng. Chem. Res., 2014, vol. 53, pp. 13320-28.

24. M. Avrami: J. Chem. Phys., 1941, vol. 9, pp. 177-84.

25. M. Avrami: J. Chem. Phys., 1939, vol. 7, pp. 1103-12.
26. L. Himmel, R. Mehl, and C.E. Birchenall: JOM, 1953, vol. 5, pp. 827-43.

27. J. Paidassi: Acta Metall., 1958, vol. 6, pp. 778-80.

28. M. Davies, M. Simnad, and C. Birchenall: JOM, 1951, vol. 3, pp. 889-96.

29. H. Lepp: Am. Miner., 1957, vol. 42, pp. 679-81.

30. U. Colombo, G. Fagherazzi, F. Gazzarrini, G. Lanzavecchia, and G. Sironi: Nature, 1964, vol. 202, pp. 175-76. 